\title{
Gabriel Okara's The Voice as Social Discourse: A Lexico-Semantic Perspective
}

\author{
Ebi Yeibo \\ Department of English and Literary Studies \\ Faculty of Arts, Niger Delta University, Wilberforce Island, Bayelsa State, Nigeria \\ E-mail: eyeibo@gmail.com
}

Received: February 25, $2011 \quad$ Accepted: May 3, 2011 doi:10.5539/ijel.v1n2p213

\begin{abstract}
Previous linguistic studies on Gabriel Okara's The Voice have concentrated on the experimental technique of transliteration which the author adopted in the text, in response to the lingering problem of language in African literature. Such studies have paid little attention to discourse features used by the author, which are critical to the characterization of the language of the text. With Halliday's systemic functional grammar, within the broad discourse-stylistic theoretical framework, as the analytical model, this study, therefore, examines the text as social discourse, focusing on paradigmatic and syntagmatic relations such as synonymy, antonymy, hyponymy and collocation, respectively, which help the author not only to convey meaning, but also to achieve cohesion and coherence in the text. The study enhances the understanding and interpretation of the language of Gabriel Okara's text in particular and literary discourse in general.
\end{abstract}

Keywords: Gabriel Okara, The Voice, Discourse-stylistics, Social discourse, Literary discourse, Lexico-semantic

\section{Introduction}

According to Hornby (2000), Discourse is

...the use of language in speech and writing in order to produce meaning; language that is studied, usually in order to see how different parts of a text are connected...

The foregoing definition implies that discourse is concerned with linguistic structures that are not only larger than the sentence, but which also have unity and connectedness in meaning. This, in turn, implies two basic forms of discourse: spoken and written, both of which have identifiable communicative function. It, therefore, becomes apparent that discourse involves the use of language as an interactive tool which involves the speaker and the listener, on the one hand and the writer and the reader, on the other. The fundamental point is that, in both instances, we can only decode the meaning intended by the communicant, not from a single sentence, but from a vast range of variable sentences. Hence David Crystal (1987) avers that the term shows “...how sentences work in sequence to produce coherent stretches of language". This opinion is corroborated by Stubbs (1983:1) in his definition of the concept as:

... the organization of language above the sentence or above the clause and therefore... larger linguistic units, such as conversational exchanges and written texts.

Another fundamental point is that the communicative meaning of any discourse is invariably conditioned by the socio-cultural context. This is because the language of discourse functions within a given pragmatic framework, as no language operates in a vacuum. Gregory (1978:109) puts it aptly when he opines that every discourse has "a place within a framework of human social activity other than that of itself". Stubbs (1983) contends that it "... is concerned with language... in social contexts and in particular with interaction or dialogue between speakers". In David Crystal's (1987) view, the concept involves:

... more complex exchanges, in which the participants' beliefs and expectations, the knowledge they share about each other and about the world, and the situation which they interact play a crucial part. 
Context is so important in discoursal study that Schiffrin (1987:3) believes that it is basically concerned with "context and communication" and operates on the following assumptions:

i. $\quad$ Language always occurs in a context

ii. Language is context sensitive

iii. Language is always communicative

iv. Language is designed for communication

On his part, Oyeleye (1997) opines that it is the point at which “...the dynamism of language relates verbalization to actual experience. Here language transforms itself to become a meaningful part of our human social behaviour". In fact, this is the whole idea of social discourse; hence literature is regarded as a form of social discourse. Oyeleye (Ibid) corroborates:

Literature is, for us, a discourse, in fact, a social discourse, (because it) is in varying degrees, defined and controlled by the social institutions within which it is embedded.

The implication of this phenomenon is that we can only grasp and interpret the meaning of a given discourse if we understand the social, cultural, conversational and personal contexts that gave birth to it (Polarry, 1979; Tannen, 1984)

This paper seeks to establish Gabriel Okara's The Voice as a form of social discourse. Specifically, it examines how the writer has used lexis and semantics to achieve his artistic target. We seek to show that lexis and semantics have text-binding and cohesive value, apart from their potentials for integrating with other elements of language, in definite socio-cultural contexts, to encode the message of a text.

\section{Theoretical Preliminaries/Literature Review}

In the preceding section, we have tried to establish literature as a form of social discourse, in the sense that literature generally uses linguistic structures beyond sentence boundaries, which are meaningful only in defined contexts. The question that naturally bothers our minds is: what exactly are the formal features or characteristics of discourse? Schifrin (1987:6) has identified three main "properties" of discourse viz:

$\begin{array}{ll}\text { i. } & \text { Structure } \\ \text { ii. } & \text { Meaning } \\ \text { iii. } & \text { Action }\end{array}$

Structure refers to the internal constituents of language and their organization into meaningful patterns. The relevant point here is that discourse is characterized by such internal linguistic constituents or categories such as morphemes, clauses and sentences which operate within a given social or cultural framework, to convey a specific textual meaning. Instructively, different scholars have advanced different notions about the structure of discourse. While scholars like Harris (1952) and Dijk (1972), for instance, believe that discourse study is not different from structural linguistics or transformational generative grammar, respectively, other scholars like Linde and Labov (1975), and Linde and Goguen (1978), believe that the structure of a given discourse is determined by or modeled after the communicative context.

On the level of meaning, lexical elements are used within discourse to link constituents together and endow them with coherent and interpretable meaning. Gabriel Okara's The Voice, for instance, as we shall show in subsequent sections, displays such elements. We shall see that linguistic categories such as pronouns, adverbs and conjunctions help to create discourse, not because they have been distributed according to conventional rules, but because they act as instruments for building and linking the various aspects of the discourse to create distinctive meaning.

Action as a property of discourse, at another level, refers to the functional value of language. In specific terms, it refers to the goals and intentions of the speaker or author, as the case may be, and how language is exploited to perform actions that are instrumental to the accomplishment of these goals. Here we are concerned with "how language works and what it does, rather than what language is" (Oyeleye, 1997). Language can be used to perform several functions (Halliday, 1970). In performing these functions, however, there are extra-textual conditions, linguistic or non-linguistic, which are necessary for the analysis of the language of discourse. This brings us to the context of situation, which also leads to such areas as literature as social discourse. It also extends to such areas as: "Speech act theory", i.e. how to do things with words, (Austin 1962; Searle, 1969); "Conversation Analysis" (Van Dijk, 1985:1-7); and the "ethnography of communication' (Baumen and Shezer 
1974, 1982) and (Saville Troika, 1982).

Discourse is often discussed along formalist and functionalist paradigms (Schiffrin 1994:20). In formalist paradigm, also known as structuralist paradigm, Discourse is described as a particular unit of language above the sentence. In functionalist, also known as emergent or interactive paradigm (May et al, 1992), Discourse is described as a discipline which focuses on language use. These definitions underpin the differences between formalist and functionalist approaches to Discourse Analysis. As summarized by Leech (1983:46), formalists tend to regard language primarily as a mental phenomenon while functionalists regard it primarily as a social phenomenon. Another fundamental point is that approaches to Discourse Analysis are inevitably heterogeneous (Bright 1992). This is because it is difficult to pin it down to a single mode of analysis; it can be applied to different genres and modes of language use and distinctive theoretical data, which may either be written or spoken. However, most of the approaches are unified in their pre-occupation with a common interest - looking beyond sentence boundaries. Bright (1992) observes that this explicit interest leads to some common agreements on:

...the general kinds of data that are of interest, appropriate methodologies

for handling and interpreting this data.

Apart from lexico-semantics (which is the focus of the present study), Discourse Analysis also examines phonology, syntax, and other related concepts in a specific discourse situation. Discourse, by its nature, provides a concrete social and psychological ambience for the explication of such formal abstractions. It also takes cognizance of different styles used by authors to achieve cohesion and coherence within a text, as we shall show in this study.

The focus on lexico-semantics is in itself significant. Apart from delineating lexis and semantics as autonomous levels of language use, such as phonology and syntax, it also shows the functional relationship between the two concepts. Ajulo (1994) captures this relationship when he quotes Darbyshire (1967:139) that lexis is "the branch of linguistics which deals with the major units of language and carries the main burden of referential meaning". McCarthy and Carter (1988) express a similar view viz:

Much of what has been written concerning lexis over the years has assumed that the proper place for discussion of the subject is within semantics.

Bloomfield (1933) extends this thesis a little further when he posits that the semantic aspect of language use is directly linked to the lexical and grammatical system in the sense that it is "...ordinarily divided into grammar and lexicon”. Halliday (1978:79) echoes a similar viewpoint inter alia:

The semantic system is an interface between the linguistic system and some higher-order symbolic system. It is projected unto or realized by the lexico-grammatical system.

In this study, we shall adopt the functional approach to discourse analysis- analyzing units of language which work in sequence to produce coherent and cohesive meaning, in a given social and pragmatic context. Against this backdrop, Halliday's systemic functional model, within the broad discourse-stylistic theoretical framework, would be used as the analytical model for our analysis of the text. This model is not only functional but is also sociological, in the sense that it takes care of syntax, lexis, pragmatics, and discourse and describes the various ways in which language in use reflects social meaning, all of which are relevant for the present study.

A critical fact is that, no scholar had used the discourse-stylistic theoretical framework in the study of Gabriel Okara's The Voice. The two-pronged model is a new area of research within the functional linguistic tradition. Basically it is concerned with the identification, description and explanation of stylistic features in a given discourse; hence it is a discourse-based stylistics. The crux of the model is that, as Opara (2005) put it, "while Discourse analysis analyses WHAT is communicated in Discourse, stylistics analyses HOW it is communicated" (emphasis mine). Unlike other modern linguistic models, which study invented or isolated aspects of language, Discourse-Stylistics examines the form and function of linguistic constructs which are beyond the sentence, in specific social, cultural or historical contexts, as explored in the given discourse. The critical point is that, the model enables the analyst to establish both the discourse and stylistic features in the text, by exploring the network of interdependences among linguistic and extra-linguistic features, which help the text not only to mean, but also to achieve cohesion and coherence.

Critical works on The Voice have concentrated on the technique of transliteration adopted in the text. In his introduction to the novel, Ravenscroft (1969) remarks that, as a result of this experimental technique, the text had a mixed reception and that some African reviewers found its unconventional use of the English language uncomfortable. The scholar adds that reviewers abroad were also partly nonplussed by the language and curious 
about its strange symbolism. This situation could have engendered the initial cold feet developed by critics, and the awful misunderstanding of the linguistic and cultural value and significance of The Voice in African literature (Iyasere, 1982). However, Duruoha (1992) observes that, "a growing volume of critique on this novel is emerging". Previous linguistic works on the text include: Shiarella's (1970) "Gabriel Okara's The Voice: A Study in the Poetic Novel", Burness' (1972) "The Voice: Stylistic Innovation and the Rhythm of African Life", Okiwelu's (1987) “Gabriel Okara: The Voice and Transliteration", Scott's (1990) "Gabriel Okara's The Voice: The Non-Ijo Reader and the Pragmatics of Translingualism", and Duruoha's (1992) "Form as Metaphor in Gabriel Okara's The Voice". The Significant point is that none of these works examines the text as social discourse, using the discourse-stylistic theoretical framework.

\section{A Brief Biography of the Author}

To fully appreciate the significance of the linguistic experiment in Okara's The Voice, it is imperative to peep into the background of the author. This will expose us not only to the linguistic and socio-cultural or ancestral origins of the writer, but also to his distinct personality, interests, and place in modern African literature, which are crucially relevant to our understanding and appreciation of the linguistic experiment in the text.

Born in April 24, 1921 in Bumoundi town in Ekpetiama clan of Bayelsa State of Nigeria, Gabriel Imomotimi Okara is one of the earliest exponents of African literature in English. After obtaining a Higher School Certificate (HSC) at Government College, Umuahia, he became a book-binder, autodidact, administrator, and Biafran nationalist. K.E. Senanu and T. Vincent (1976) comment that from this point in his life:

...okara developed a remarkable personality by dint of personal tuition, reflection and deep interest in literature generally and in the language and culture of his people.

From the foregoing comment, we can observe that, though he later studied comparative journalism at Northwestern University, Evanston, USA, Okara had developed interest in literature generally and his linguistic and cultural roots in particular at a very early age. This interest must have motivated him to do extensive research into these two areas of study. There is no doubt that this would have equipped him with the intellectual resources to fashion out a new linguistic idiom to interpret his bilingual and bicultural environment. It is, therefore, no coincidence that the most significant thing that marks out Okara in African literature is the experiment with language (i.e. transliteration) in his The Voice.

Apart from this novel, the writer is also one of the earliest and foremost poets in Africa. His poetry has won major local and international awards, including the Commonwealth poetry prize (1979) and the Nigeria (NLNG) prize for literature (2005).

\section{Socio-Cultural Context of Okara's Text}

For a thorough understanding and appreciation of language of the text, we need to situate it in its appropriate socio-cultural context. The story of the voice centres around Okolo, the protagonist, who returns to his home town Amatu, after studying abroad. He is nauseated by the degree of moral corruption, deceit and materialism which have taken over the society and decides to devote his life to a conscious struggle to re-instate sanity and moral order. He seeks to achieve this goal by going around (both in Amatu and Sologa), to ask the leaders and the people if they have got "it". In the context in which Okolo uses it, "it" represents goodness, truth, faith, in fact, the meaning of life. Chief Izongo and the elders feel threatened by his knowledge and straightforwardness and by his awkward question "have you got it?" They decide to declare him a lunatic and ostracize him. The degree of moral decay and social corruption in the society is illustrated by the contrast between the protagonist, Okolo (which, translated means "the voice"), who is an epitome of moral rectitude and uprightness and thus, represents Light, and the hierarchy of elders who are led by Chief Izongo, and who represent Darkness. Thus the language of the discourse would be explored against the background of this frosty relationship amongst the major characters. Specifically, this forms the context of situation, which informs our study.

\section{Textual Analysis}

With the foregoing preliminary insights, we shall now examine the linguistic elements which help the author to convey the meaning of the text and also achieve cohesion and coherence. Specifically, the analysis will be carried out under the following headings: semantic fields, thematic development, context and meaning, lexical reiteration and cohesion, hyponymy and cohesion, synonymy and antonymy as elements of cohesion, collocation and cohesion, and other aspects of lexical cohesion.

\subsection{Semantic Fields}

We shall begin the textual analysis by identifying lexical sets, or what may be termed "set membership", according to semantic fields. This has to do with compartmentalizing lexical choices whose meanings share 
common features. This is important because each compartment deals with a particular aspect of meaning, as a clue to the overall thematic concerns of the text. It was the German linguist, Professor Trier, who introduced the notion of semantic fields, suggesting that the vocabulary of a language is "an integrated system of lexemes interrelated in a sense" (Lyons 1977:253). Lehrer (1994:15) echoes the same idea inter alia:

The words of a language can be classified into sets, which are related to conceptual fields and divide up the semantic space or the semantic domain in certain ways.

As a result of the restrictive scope of this study, we shall limit ourselves to only some of the lexical items in the semantic fields that would give us considerable clues about the thematic pre-occupations of the text. These include:

i. Lexical items suggesting corruption and moral decadence (stinking things, smelling insides, women and money, turned world, spoilt world, etc);

ii. Materialism (cars, concrete houses, engine boats, money, etc);

iii. Hypocrisy (surface-water things, surface-water laughter, etc;

iv. Government and politics (elders, imperialists, adviser, democracy, leader, etc);

v. Darkness (groping, locked-up inside, witch, bad bottom, ugly inside, witchcraft, etc);

vi. $\quad$ Place (Amatu, Sologa, town, village, abroad, America, etc;

vii. Light, truth and integrity (“it", sweet inside, Jesus, open inside, plain inside etc);

viii. Time (past, new time, old times, many, many years, etc);

ix. Education (book, M. A., Ph.D, Universities, big school house, etc).

\subsection{Thematic Development}

Having shown the different compartments of meaning, we can now validate our earlier hypothesis that the meaning of the text is structured into two distinct parts: Light and Darkness. It follows, therefore, that the novel thrives on a running battle between the forces of light and the forces of darkness. This is the superordinate conflict, which subsumes every other conflict in the text.

A careful study of the lexical sets shows that they reflect this phenomenon. The result is that the author's choice of lexemes is aptly guided by their semantic significance in relation to textual function. For instance, sets like "corruption and moral decadence", "materialism" and hypocrisy" can be categorized under Darkness, while "truth and integrity" can be classified under Light. On the other hand, lexical sets such as "education", "time", and "place", constitute the physical and social conditions which are being exploited and manipulated by both forces (i.e. light and darkness), for the promotion of their parallel causes.

Instructively, while Chief Izongo, the elders, the white superintendent of the "listeners" at Sologa and the "Listeners" etc, prosecute the agenda of "darkness", the agenda of "light" and social change, on the other hand, is being championed by Okolo, the conscience (voice) of society in conjunction with Tuere and supported by Ukule, the cripple. And, like the biblical statement "heaven and earth shall pass away; but my word shall not pass away "(Luke 21:33), the spoken word of truth in this text is portrayed as timeless. While the material things, like Solomon's "vanity of vanities; all is vanity" (Eccl. 1:2), are portrayed as transient or ephemeral. Tiri echoes this theme inter alia:

Money may be lost forever but words, teaching words, are the same in any age (p. 52). (italics mine).

\subsection{Context and Meaning}

In Okara's The Voice, context plays a fundamental role in determining the meaning of the text. This is an important aspect of social discourse. For instance, lexical choices become meaningful only if we apply our shared knowledge of the world of the text. This fact explains why linguistic constructs such as "His head is not correct" (p. 27), "search with all his inside" (p.23), and "Okolo had no chest" (p.23), become meaningful only if we consider the sociolinguistic and psycholinguistic context in which the work is situated.

We also find that, ordinary lexical items such as "women", "money", "car", "cloth", and concrete houses", do not evoke any corrupt implication, for, as human beings, we all need them for our daily survival and can acquire them through decent and legitimate means. But the world of the text informs us that they have corrupt connotations.

Again, nothing would give away usages like "we are all church people" (p.30) or "we are all know-God people" 
(p.32) as hypocritical expressions if they are not situated in a definite pragmatic context. But our knowledge of the lingering conflict between the agents of Satan and the Angels of light in the text, enable us to appropriately interpret them.

The main point is that, in this text, meaning is determined by the pragmatic motive of the user, as each character has his/her own interpretation of, or disposition towards life. Hence Chief Izongo wantonly proclaims Okolo, the ambassador of truth and integrity, a "mad man" or a "stinking thing" (p.72). The conflict of the text is implicitly generated by this phenomenon. Clearly, there is a conflict of interest and thus, a conflict of disposition and attitude, which results in a conflict of language and meaning. Obododinma (1989) captures this phenomenon, quite aptly, when he talks about "doing battle with words... the battle is a battle of meaning". Okolo confirms:

Yes, each one has a meaning of life to himself. And that is perhaps the root of the conflict (p.111).

A knowledge of the foregoing situational context is necessary to accurately decode the meaning of lexical choices in Okara's The Voice. We are, therefore, guided by Halliday and Hassan's (1976) distinction between "general" and "instantial" lexical relations in this study. According to these scholars, "general" lexical relations refer to those, which would still be valid out of the textual context, while "instantial", on the other hand, refer to those which are valid or relevant only within the context of the text. As this work is discourse-based, we have restricted our study to the latter, that is, lexical relations within the instance of the text. This means that lexical relations, such as synonyms and antonyms in this study, are derived form their semantic implications and their interchangeability or otherwise, in contexts within the text. This is because, as Carter and McCarthy (1988:203) elaborate:

The relations we call instantial are labels for lexical values rather than abstract meaning; they are the properties of particular texts... a chain which would not necessarily be recognized in a dictionary or thesaurus, but which is clearly part of the lexical structure of the text.

\subsection{Lexical Reiteration and Cohesion}

We have already mentioned that discourse is basically characterized by linguistic units such as morphemes, words clauses and sentences. The point is that a sequence of sentences form discourse, and sentences are composed of words. In Okara's The Voice, we find that even single content words treated in isolation can give us significant clues to the meaning of the text.

The foregoing means that, apart from syntagmatic relations (such as collocations) and paradigmatic relations (such as antonyms, synonyms and hyponyms), all of which are composed of lexical items; we can also deduce the thematic concern of the text through single words. For instance, "locked-up" and "groping", suggest Darkness, while lexemes like "plain" and "open", suggest truth and integrity, which we have classified under Light. Lexical items like "stinking", "smelling," drunkenness", "spoil", and "foul", etc, reflect moral decadence, while "money" and "cars" suggest materialism, all of which we have classified under Darkness. A fundamental aspect is that, the author consciously repeats these lexical items to make his message run through the text. Lexical reiteration has to do with repetition of the same lexical items within a text. Apparently, this strengthens cohesion and also foregrounds the semantic import of lexical choices. Cohesion, on the other hand, infers:

...connectedness of meaning, the feeling that something is a text and not a random set of sentences or utterances (McCarthy and Carter, 1988).

Lexical cohesion is, therefore, a deliberate device used by authors to unify the meaning of a text. It thrives on consistency of reference (i.e. Anaphoric and Cataphoric references) within a text. Halliday and Hassan (1976: 208) have suggested that such unifying lexical relations can be studied under the following headings:

a. Reiteration

$$
\begin{array}{ll}
\text { i } & \text { Same word repetition } \\
\text { ii. } & \text { Synonym or near-synonym } \\
\text { iii. } & \text { Super-ordinate } \\
\text { iv. } & \text { General word }
\end{array}
$$

b. Collocation

The following are some specific contexts or instances of lexical reiteration in Okara's The Voice

i. If an egg rolls against a stone, the egg breaks and if a stone rolls against an egg, the egg breaks. So we shall talk. We are egg be (P. 121). 
ii. "...we fear no the elders". Turere's voice rang out to the crowd. "we fear no one. It is they who fear us. By fearing us, they fear the straight thing". (p. 121/122).

iii. So whether you agree or do not agree means nothing to me because one whose head is not correct never agrees that his head is not correct (p.38).

In context (i) above, Abadi persuades Chief Izongo to be patient with Tuere (Okolo's soulmate) and Okolo, so that they would exhaust their anger. The repetition emphasizes that, being a stronger force, they would eventually truncate or smash the duo's (Tuere and Okolo's) dreams of moral and spiritual refinement. Context (ii) Etches the running centrality of fear to the message of the text. Tuere is the speaker and the subject of reference is Chief Izongo and his elders. The recurrence of the lexical item "fear" foregrounds its semantic import in the text, as it is the fear of Okolo and his "it" that precipitates its conflict and even leads to the ultimate tragedy (i.e. the death of Okolo). In context (iii) above, chief Izongo declares that he does not need Okolo's consent to believe that the latter is mentally sick, to look for "it" in a "turned world". It shows the desperation with which Chief Izongo operates in the text. A knowledge of this trait is vital because it serves as a semantic clue to his overall demeanour and misdemeanour in the text.

Apart from the specific instances explored in the foregoing contexts, there is also a recurring reiteration of some lexical items throughout the text. Our classification here is guided by Halliday's (1966:159) view that lexical items can be "simple", "compound" and "phrasal", in relation to how they constitute units of meaning. Some of these are "stinking thing," "smelling inside", "straight thing", "bad word", "questioning word" and "it". Instructively, the repetition underscores their centrality and unifying potentials to the meaning of the text.

\subsection{Hyponymy and Cohesion}

Hyponymy is a sense relation which obtains within specific and general lexical items such that the specific is included in the general. For instance, "dog" is included in "animal". In this phenomenon, there is always a super-ordinate lexeme with reference to which the subordinate terms can be defined. Cruse (1995) believes that:

They are a basic way of creating taxonomy-like relationships within fields, that correspond to social and psychological concepts. (see Carter and McCarthy, 1988:26).

In Okara's The Voice, the most prominent general or super-ordinate term is the object of Okolo's quest "it" which recurs throughout the text. "It" is the pivot of the text, the tiny but curious term around which the entire meaning of the text is woven. It is the object for which Okolo sacrifices himself in the text. Thus it stands for truth and integrity and for sanity, moral rectitude and spiritual rebirth, all of which can be termed co-hyponyms under the general term. In fact, "it" (a pronoun functioning as an abstract noun), is a striking term of inclusion, which covers every property of Light in the text. On the other hand, its text-binding quality can be visualized in the sense that it is also the object against which the antagonists in the text desperately struggle. It is "like the voice of a mosquito which had driven even sleep out of their eyes" (p. 19). It is pertinent to mention that "it" is translated from the Ijaw word "Iye", which means "something". Thus it is the "thing" that distinguishes Okolo's "meaning of life" (P.111) from that of Chief Izongo and his cohorts. In this way, the conflict of the text, which is every central to the overall meaning of Okara's novel, is lucidly developed.

\subsection{Synonymy and Antonymy as Elements of Cohesion}

We had earlier suggested that lexical items which imply Darkness and Light are the most sweeping and pervasive in Okara's The Voice. However, at another interpretative level, these lexical items connote "Synonyms" and "Antonyms". Carter and McCarthy (1988:201) believe that:

Surface cohesive ties such as synonyms (and antonyms) should not be looked on just as interesting formal patterns but as manifestations of how we are making sense of the message of the text.

A close examination of the lexical items classified under Darkness, for instance, would tell us that they imply an array of synonyms. These include: "bad bottom", crooked word", "groping" and "locked-up inside". We find another chain of synonyms signifying Light in forms such as "good bottom", "straight words", "open onside", "plain inside", "straight things", and "it". A reiteration of these lexical items throughout the text helps to establish and sustain the meaning of the text. The point is that if we pick out all the synonyms signifying Darkness that are consistently being reiterated in the text, and do same to those items signifying Light, and examine them separately, we would be able to make some sense of how meaning is patterned in the text. We would discover that the meaning of the text is structured into two distinctive parts: Light and Darkness.

Again, if we juxtapose the two set of items (i.e. representing Darkness and Light) enumerated above, we would find a chain of opposites. Antonymy thrives in oppositeness of meaning. This means that it thrives in conflict, 
and conflict is a permanent feature of the meaning of literary discourse. Specifically, Okara's The Voice thrives in a running battle between the forces of light and the forces of darkness. This is the super-ordinate conflict that subsumes every other conflict in the text. The implication is that the author has utilized synonymy and antonym not only as meaning-encoding devices, but also as elements of cohesion, because the cumulative meaning of the text is specified by the relatedness and difference between such lexical elements.

\subsection{Collocation and Cohesion}

Collocation refers to the "company lexical items keep --- their propensity for particular neighbours and environments" (see Halliday et al, 1964). According to Carter and McCarthy (1988:32), J. R. Firth holds the view that collocation, as an aspect of meaning, operates as "an abstraction at the syntagmatic level and is not directly concerned with the conceptual or idea approach to the meaning of words" (1951:57). Instructively, this is a view, which separates lexis from semantics, but whch generally contributes significant meaning and cohesion to discourse. For instance, in Okara's The Voice, we have a wide range of collocations that runs through the entire work, a recurrence which has much to do with textual function. The following examples prove the point:

$\begin{array}{ll}\text { i. } & \text { Turned world } \\ \text { ii. } & \text { Stinking thing } \\ \text { iii. } & \text { Spoilt world } \\ \text { iv. } & \text { Open inside } \\ \text { v. } & \text { Locked-up inside } \\ \text { vi. } & \text { Straight thing } \\ \text { vii. } & \text { Surface-water laughter, etc. }\end{array}$

The salient point is that, as we have shown earlier, all these sets help in developing the themes and also help to tie the cumulative meaning of the text together.

\subsection{Other Aspects of Lexical Cohesion}

A close look at the text shows that, within the framework of lexical semantics, there are other lexical ties, which create a highly coherent and effective pattern of meaning for the text at the sentence level. Dijk (1977) hinted at this situation inter alia:

The study of relations between sentences in discourse... shows how the meaning and reference of sequences depend on the meaning and references of their component sentences.

We shall illustrate this phenomenon, by exploring lexical ties such as the use of structural words (like pronouns and conjunctions); references (such as anaphoric and exophoric); repetition, and presupposition, in the passage below:

You know time finishes. Yet when my father's time finished and he went away, you people put it on my head. And when the time of my mother finished and she went away, you said I killed her with witchcraft. Whose time finishes not? Whose time finishes not? Our time is finishing just as the time of some of your relations (p.30).

In the passage above, we find that various lexical items are implicitly dependent on one another for an effective transmission of the textual meaning. Lexical relations such as this imply that the meaning which is presupposed in one term can only be traceable in another term. This is the whole idea of textual cohesion. For instance, we find that the pronoun "he" in the second sentence refers to "father" while "she" refers to "mother". This is an example of anaphoric reference. We find an instance of exophoric reference in "the time of some of your relations". The relations are clearly outside the environment of the discourse. We find repetition in "whose time finishes not?" "whose time finishes not?" we also find that what is presupposed in "time finishes" is traceable in phrases such as "he went away" and "she went away".

Apart from the foregoing, we can also see connectedness in items such as: you, mother, father, he, she, our, relations, etc, that characterize the text. All these items depict or reflect consanguinity.

\section{Conclusion}

From the foregoing study, we have shown that text-making is a conscious process, in the sense that every relation of meaning in discourse is achieved by a deliberate combination of lexical choices. Specifically, we have shown that Gabriel Okara's The Voice is a form of social discourse, by examining the various lexical relations 
the author has deliberately deployed, within the framework of the socio-cultural world of the text, to encode and unify its meaning.

\section{References}

Ajulo, E. B. (1994). Investigating Lexis: Problems of Theory and Pedagogy. Ibadan. Stirling-Horden Pub. Nig. Ltd.

Austin, J. L. (1962). How to do Things with Words. Oxford. Clarendon Press.

Bloomfield, L. (1933). Language. New York. Hold, Rinehart and Winston.

Bright, W. ed. (1992). International Encyclopedia of Linguistics, Vol. 1. New York. Oxford University Press.

Carter, R. \& McCarthy, M. (1988). Vocabulary \& Language Teaching. London. Longman Group Ltd.

Cruse, D. (1977). The pragmatics of Lexical Specificity. Journal of Linguistics, Vol. 13, No. 2. doi:10.1017/S0022226700005363, http://dx.doi.org/10.1017/S0022226700005363

Crystal, D. (1987). The Cambridge Encyclopedia of Language. Cambridge. Cambridge University Press.

Darbyshire, A. (1967). A Description of English. London. Edward Arnold.

Dijk, V. (1977). Text \& Context: Explorations in the Semantics \& Pragmatics of Discourse. London. Longman Group Ltd.

Duruoha, S.I. (1992). Form as Metaphor in Gabriel Okara's The Voice. In Oye: Ogun Journal of Arts, Vol. V. Ogun State University, Ago Iwoye, Nigeria.

Gregory, M. (1974). A Theory for Stylistics - Exemplified: Donne's "Holy Sonnet XIV”. Language \& Style, Vol. VII. 2.

Grosz, B. (1981). Focusing \& Description in national Language Dialogues. In Joshin A. et al (eds), Elements of Discourse Understanding. Cambridge. Cambridge University Press.

Halliday, M. A. K. et al. (1964). The Linguistic Sciences and Language Teaching. London. Longman.

Halliday, M. A. K. (1966). Lexis as a linguistic Level. In Brazell, J. et al (eds) In Memory of J. R. Firth. London. Longman.

Halliday, M.A.K. (1970). Language Structure and Language Function. In Lyons, J. (ed) Horizons in Linguistics. Pelican.

Halliday, M.A.K. (1973). Explorations in the Functions of English. London. Edward Arnold.

Halliday, M. A. K. and Hassan R. (1976). Cohesion in English. London. Longman.

Harris, Z. (1952). Discourse Analysis: A Sample Text. Language, Vol. 28.

Hornby, A. S. (2000). Oxford Advanced Learner's Dictionary. Oxford. Oxford University Press.

Lyons, J. (1977). Semantics Vol. 1 \& 2. Cambridge. Cambridge University Press.

Okara, G. (1964). The Voice. London. Heinemann Educational Books Ltd.

Opara, S.C. (2005). Discourse-Stylistics of Speech in Buchi Emecheta's Prose Fiction. An Unpublished Ph. D Thesis, University of Ibadan.

Oyeleye, A. L. (1997). An Exercise in Discourse Stylistics - Exemplified: Soyinka's "Telephone Conversation". In Oladepo (ed.) Ibadan Journal of Humanistic Studies (No. 7).

Schiffrin, (1987). Discourse Markers. Cambridge. Cambridge University Press.

Scott, P. (1990). Gabriel Okara's The Voice: The Non-Ijo Reader and the Pragmatics of Translingualism. In Bjornson, R. (ed) Research in African Literature, Vol. 21, No. 3. Indiana. Indiana University Press.

Searle, J. R. (1969). Speech Acts: An Essay in the Philosophy of Language. New York. Cambridge University Press.

Shiarella, J. (1970). Gabrile Okara's The Voice: A Study in the Poetic Novel. In Clark, J.P. \& Abiola, I. (eds.) Black Orpheus. Lagos. Daily Times of Nigeria.

Stubbs, M. (1983). Discourse Analysis: The Sociolinguistic Analysis of Natural Language. Oxford. Basil Blackwell Ltd.

The Holy Bible (King James Version, 1970). Nashville. Thomas Nelson Publishers. 